UCRL-ID-119089

\title{
Broad-Band Characterization of the Complex \\ Permittivity and Permeability of Materials
}

Carlos A. Avalle

November 1994

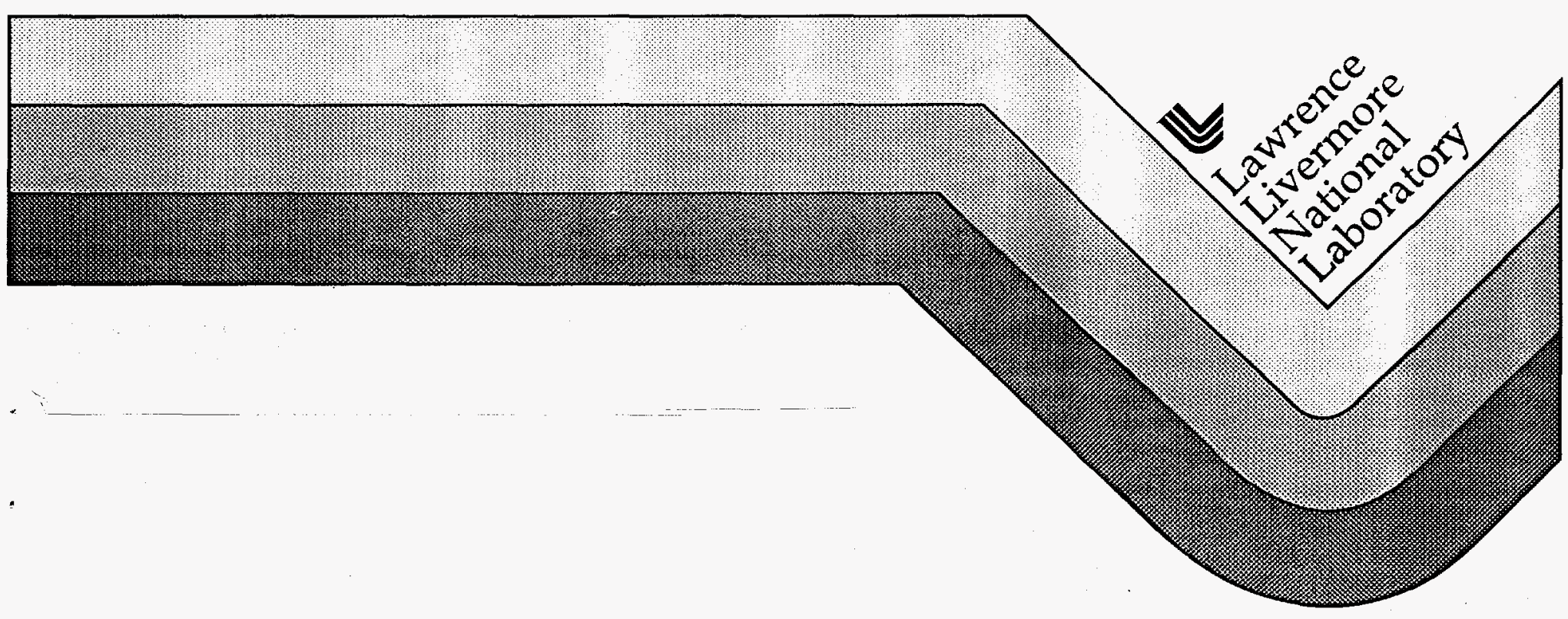




\section{DISCLAIMER}

This report was prepared as an account of work sponsored by an agency of the United States Government. Neither the United States Government nor any agency thereof, nor any of their employees, make any warranty, express or implied, or assumes any legal liability or responsibility for the accuracy, completeness, or usefulness of any information, apparatus, product, or process disclosed, or represents that its use would not infringe privately owned rights. Reference herein to any specific commercial product, process, or service by trade name, trademark, manufacturer, or otherwise does not necessarily constitute or imply its endorsement, recommendation, or favoring by the United States Government or any agency thereof. The views and opinions of authors expressed herein do not necessarily state or reflect those of the United States Government or any agency thereof. 


\section{DISCLAIMER}

Portions of this document may be illegible in electronic image products. Images are produced from the best available original document. 


\title{
Broad-Band characterization of the complex permittivity and permeability of materials
}

\author{
Carlos A. Avalle \\ Electromagnetics \& Diagnostics Group \\ Lawrence Livermore National Laboratory
}

\begin{abstract}
By employment of state-of-the-art Vector Network Analyzers, and other wide-band measurement equipment and techniques, we have the capability of measuring the complex permittivity and permeability of materials, for frequencies ranging from several tens of Kilohertz up to several Gigahertz. Measurement methods and equations for numerical determination are based on recommendations by the National Institute of Standards and Technology (NIST). The following illustrations provide an overview of our experience and capabilities.

Contact: Carlos A. Avalle, (510) 423-1178
\end{abstract}

RF characterization of materials

Various techniques have been utilized for RF characterization of materials:

1. Free Field swept CW: 1 to $20 \mathrm{GHz}$, arbitrary incidence angles

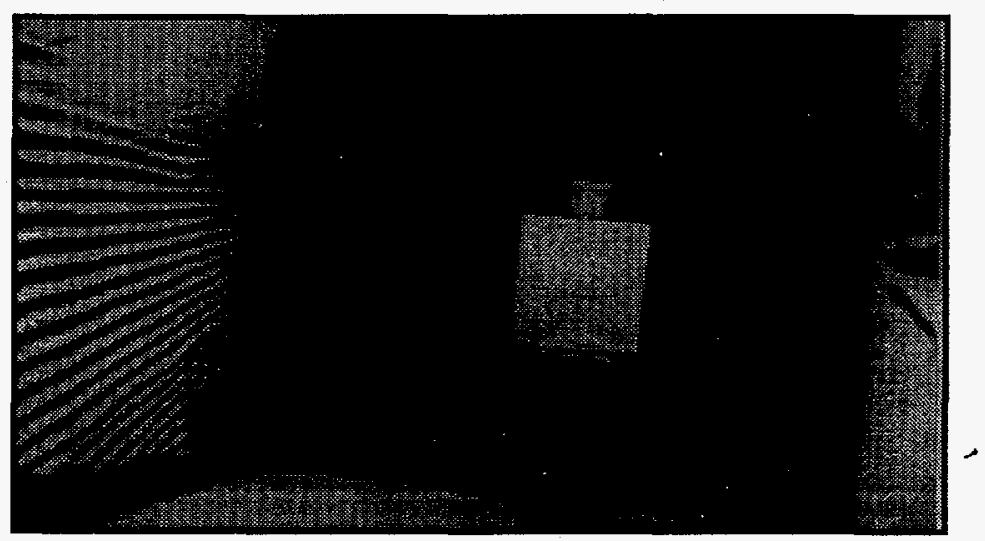

Figure 1 -- a view from the source antenna in the tapered portion of the anechoic chamber toward a reference reflector dramatizes the environment required to make free field measurements.

2. Airline swept $\mathrm{CW}: 30 \mathrm{KHz}$ to several $\mathrm{GHz}$, normal incidence 
3. Airline UWB Pulse: DC to several GHz, normal incidence

4. Microstrip: $30 \mathrm{KHz}$ to several $\mathrm{GHz}$, grazing incidence

\section{Types of materials}

- Dielectric or magnetic RF \& radar absorbers

- Thin sheets, paints, coatings

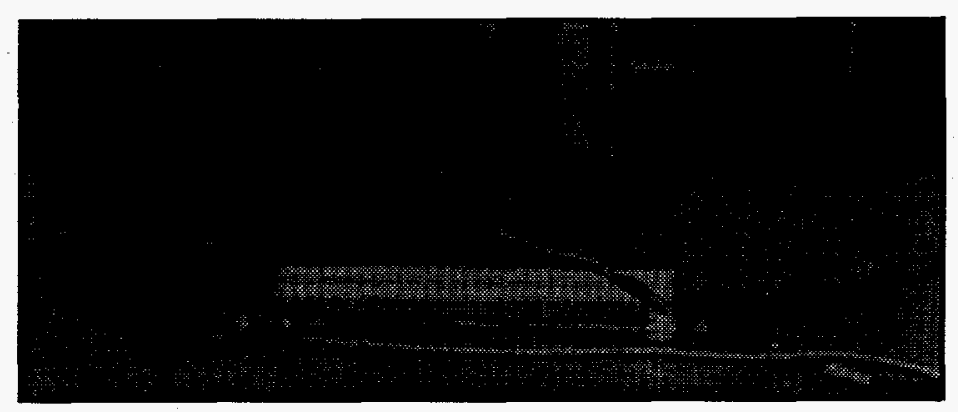

Figure 2 -- Small coaxial airline for testing RF paints and coatings.

- Castable resins

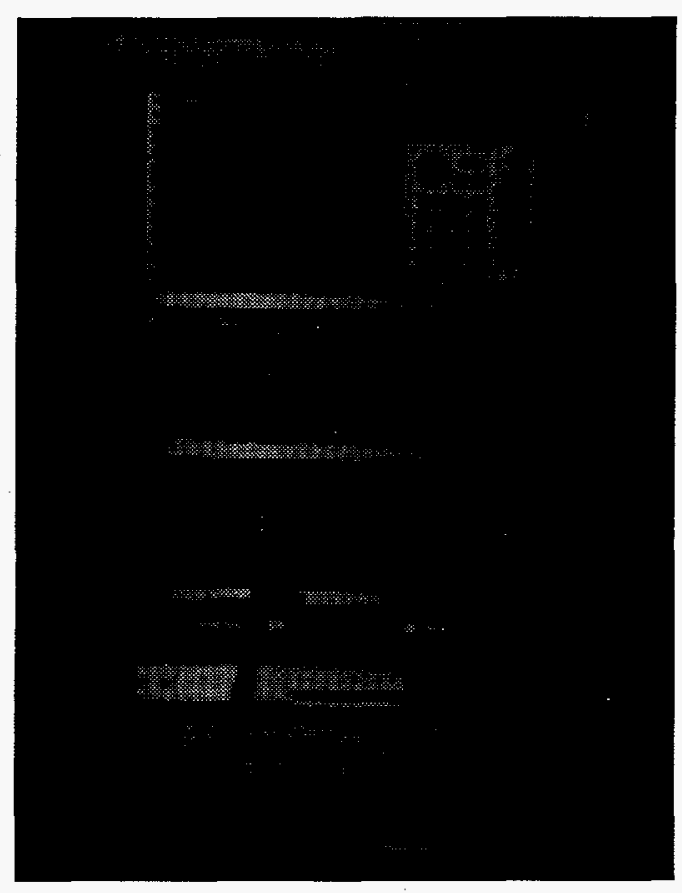

Figure $3--2$ " airline for testing castable materials (the airline is on the pull-out table in front of the HP8510 Vector Network Analyzer. 
- Foams \& low density materials

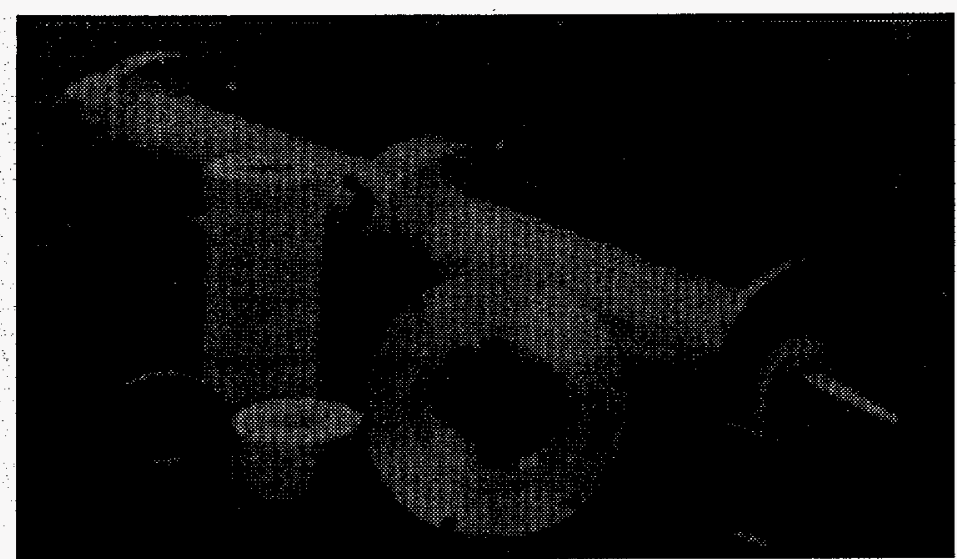

Figure 4 - 4" airline for testing low density material.

- Ceramics \& ferrites

- Carbonized fabrics

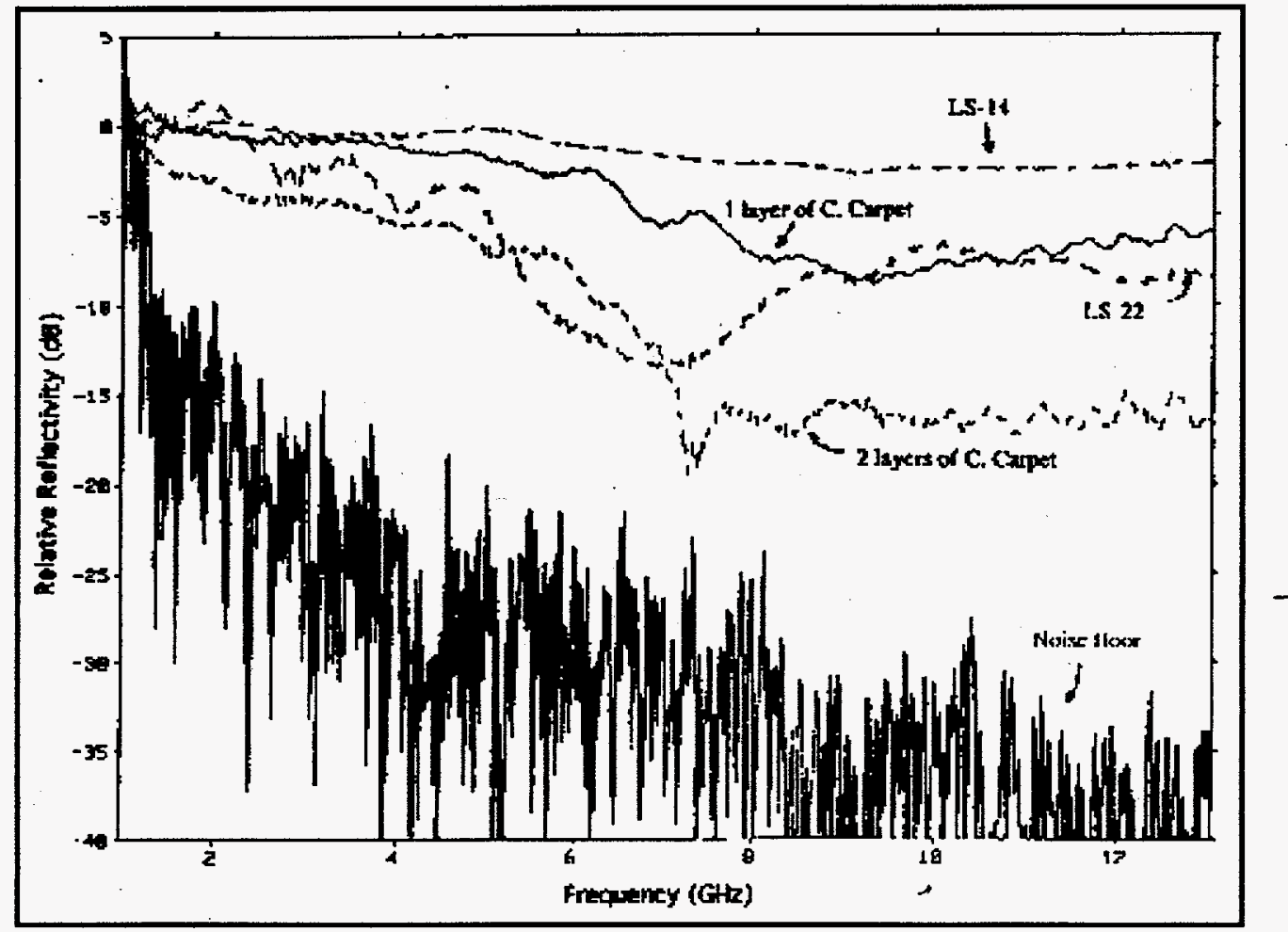

Figure 5 -- LLNL Carbonized Carpet reflectivity characteristics compare favorably against commercial absorbers. Notice that the vertical scale is the reflectivity (in $\mathrm{dB}$ ) with a frequency sweep from 1 to $13 \mathrm{GHz}$. 
- Composite

\section{Coaxial Airlines}

Coaxial airlines are used for material RF characterization by measuring the scattering parameters:

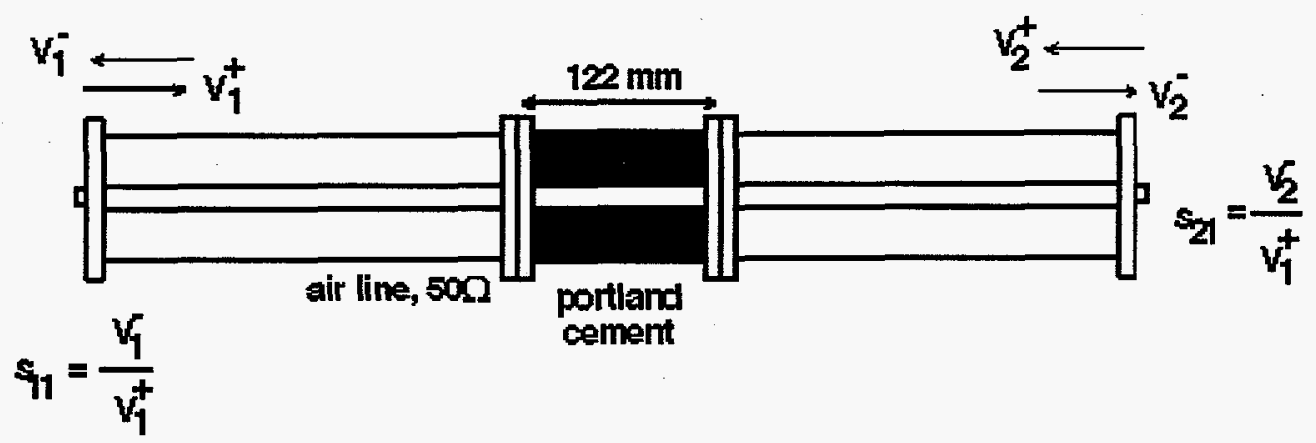

The material under test (in this case cement) is placed in a section of the air line and the scattering parameters are calculated from the transmitted and reflected waves. The insertion loss (s21) and the return loss (s11) are used in the calculation equations to find the complex permittivity and permeability.

The classical Nicolson Ross-Weir equations relate the scattering data to Complex Permittivity and Permeability. These equations have the advantage of working on dielectric or magnetic materials but the disadvantage of numerical instability at half-wavelength points. Also, the sample length and reference plane must be well known.

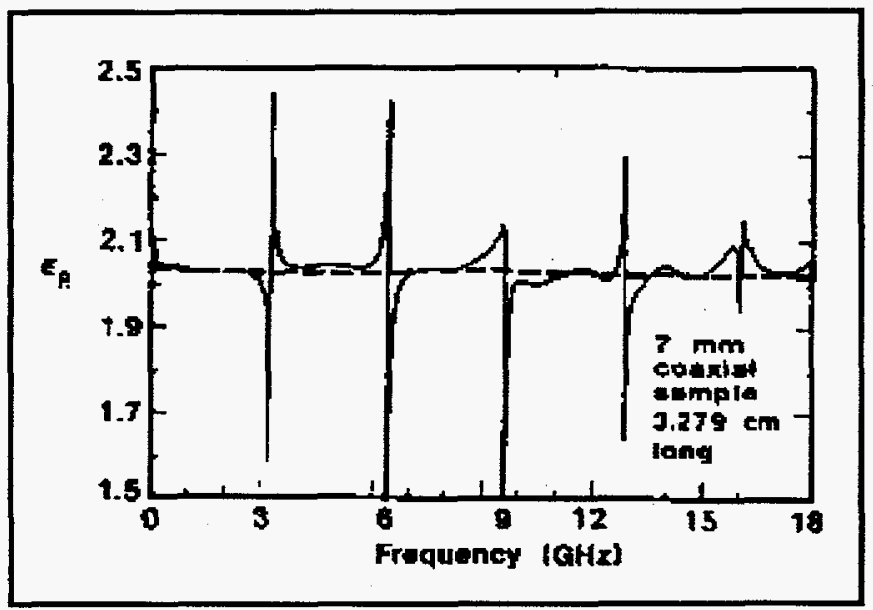

Figure 6 - notice the half-wavelength instabilities in the Nicolson RossWeir equations. 
New equations and robust algorithms derived by NIST have been adopted for Dielectric Constant measurements. These algorithms have the advantages of being reference plane and sample length independent with an improved accuracy for thin samples.

$$
\begin{aligned}
& \left|s_{21}\right|=\left|\frac{z\left(1-\Gamma^{2}\right)}{1-z^{2} \Gamma^{2}}\right| \\
& \left|s_{11}\right|=\left|\frac{\Gamma\left(1-z^{2}\right)}{1-z^{2} \Gamma^{2}}\right| \\
& \frac{s_{11} s_{22}}{s_{12} s_{21}}=\frac{\left(1-\frac{E_{R}^{*}}{\mu_{R}^{\star}}\right)^{2}}{4 \frac{E_{R}^{\star}}{\mu_{R}^{*}}} \sinh ^{2} \gamma L \\
& \frac{s_{21}}{s_{21}^{o}}=\exp \left(\gamma_{0} L\right) \frac{z\left[1-\Gamma^{2}\right]}{1-z^{2} \Gamma^{2}} \\
& s_{21} s_{12}-s_{11} s_{22}=\exp \left[\left(-2 \gamma_{0}\right)\left(L_{a i r}-L\right)\right] \frac{z^{2}-\Gamma^{2}}{1-z^{2} \Gamma^{2}}
\end{aligned}
$$

These equations were used, in conjunction with experimental scattering parameter data from the coaxial line, to calculate the complex permittivity of cement. 


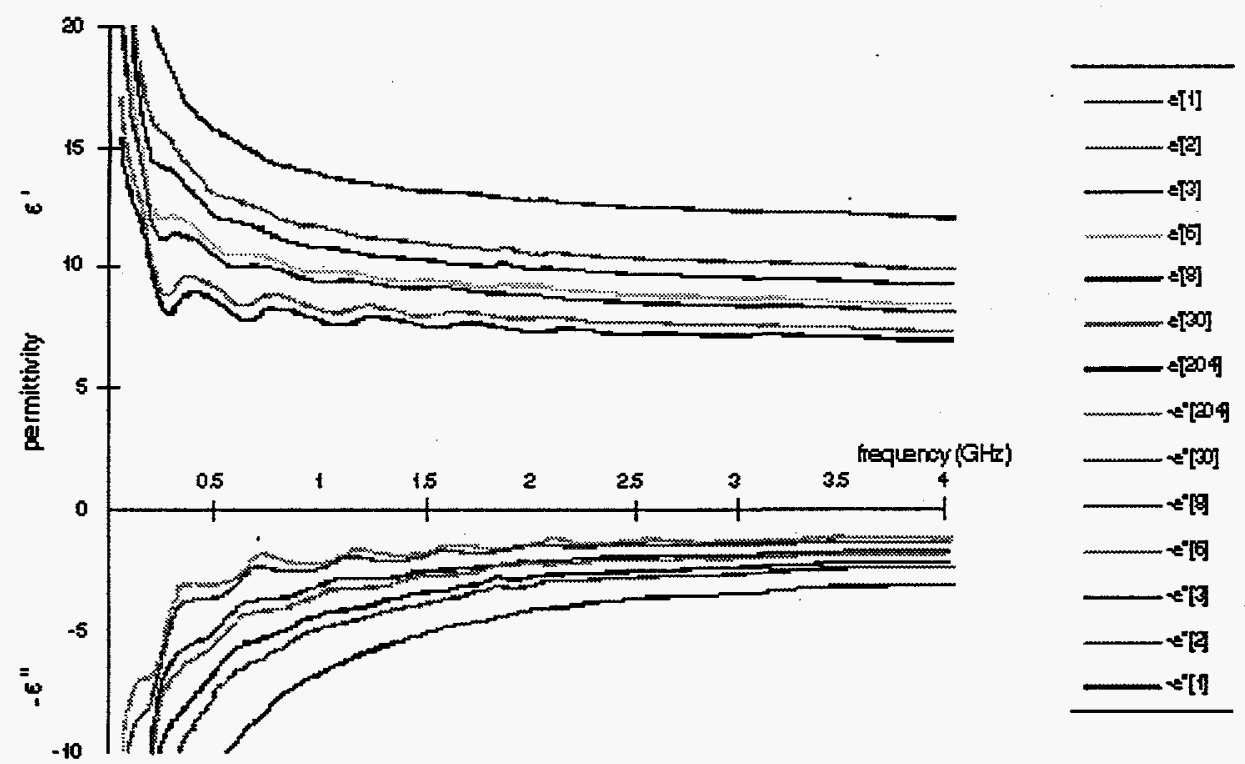

Figure 7 -- the complex permittivity for the test material is shown as a function of cure time [in days]. For clarity, the imaginary part of the permittivity is plotted in the lower half space in the plot.

Using similar equations one can also determine the characteristics for magnetic materials.

\section{Conclusions}

The utility of these new algorithms has been demonstrated and applied to experimental data. The resulting permittivity calculations do not suffer from the instabilities of the "classical" permittivity calculations and so are more suitable for broad band data.

\section{Acknowledgements}

The author would like to thank NIST for their efforts in the area of material characterization, for their work on the new equations, and specifically to D. Friday of NIST EM Fields Division for his interest in LLNL's activities.

If you have technical questions about this page, contact:

Carlos A. Avalle, avalle1@llnl.gov 